PREPARED FOR THE U.S. DEPARTMENT OF ENERGY, UNDER CONTRACT DE-AC02-76CH03073

PPPL-3818

PPPL-3818

UC-70

\title{
Tritiated Dust Levitation \\ by Beta Induced Static Charge
}

by

C.H. Skinner, C.A. Gentile,

L. Ciebiera, and S. Langish

June 2003

NM|

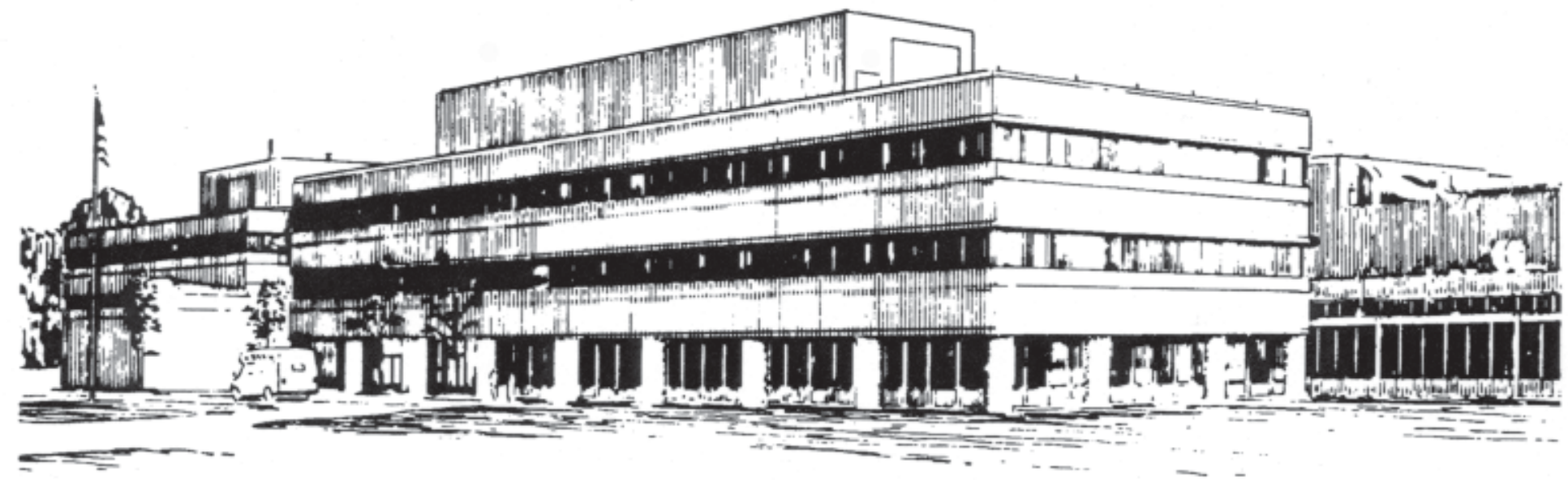

PRINCETON PLASMA PHYSICS LABORATORY PRINCETON UNIVERSITY, PRINCETON, NEW JERSEY 


\section{PPPL Reports Disclaimer}

This report was prepared as an account of work sponsored by an agency of the United States Government. Neither the United States Government nor any agency thereof, nor any of their employees, makes any warranty, express or implied, or assumes any legal liability or responsibility for the accuracy, completeness, or usefulness of any information, apparatus, product, or process disclosed, or represents that its use would not infringe privately owned rights. Reference herein to any specific commercial product, process, or service by trade name, trademark, manufacturer, or otherwise, does not necessarily constitute or imply its endorsement, recommendation, or favoring by the United States Government or any agency thereof. The views and opinions of authors expressed herein do not necessarily state or reflect those of the United States Government or any agency thereof.

\section{Availability}

This report is posted on the U.S. Department of Energy's Princeton Plasma Physics Laboratory Publications and Reports web site in Fiscal Year 2003. The home page for PPPL Reports and Publications is: http://www.pppl.gov/pub_report/

DOE and DOE Contractors can obtain copies of this report from:

U.S. Department of Energy

Office of Scientific and Technical Information

DOE Technical Information Services (DTIS)

P.O. Box 62

Oak Ridge, TN 37831

Telephone: (865) 576-8401

Fax: (865) 576-5728

Email: reports@adonis.osti.gov

This report is available to the general public from:

National Technical Information Service

U.S. Department of Commerce

5285 Port Royal Road

Springfield, VA 22161

Telephone: $1-800-553-6847$ or

(703) $605-6000$

Fax: (703) 321-8547

Internet: http://www.ntis.gov/ordering.htm 


\title{
Tritiated dust levitation by beta induced static charge
}

\author{
C. H. Skinner, C. A. Gentile, L. Ciebiera, S. Langish. \\ Princeton Plasma Physics Laboratory, Princeton, New Jersey, 08543 USA.
}

\begin{abstract}
:
Tritiated particles have been observed to spontaneously levitate under the influence of a static electric field. Tritium containing codeposits were mechanically scraped from tiles that had been used in the Tokamak Fusion Test Reactor (TFTR) inner limiter during the deuterium-tritium campaign and were placed in a glass vial. On rubbing the plastic cap of the vial a remarkable 'fountain' of particles was seen inside the vial. Particles from an unused tile or from a TFTR codeposit formed during deuterium discharges did not exhibit this phenomenon. It appears that tritiated particles are more mobile than other particles and this should be considered in assessing tokamak accident scenarios and in occupational safety.
\end{abstract}

Keywords: Dust, particles, tritium, tritium codeposition, safety, nuclear fusion. 


\section{Introduction}

Diagnosis and management of particulates in tokamaks is a 'housekeeping' area that falls in-between traditional plasma physics and plasma technology fields, however it is critical to the safe operation of next step devices. The high density, low temperature environment of the divertor plasma facilitates chemical erosion of carbon plasma facing components and a tritiated codeposited layer is predicted to accumulate at $\mathrm{nm} / \mathrm{s}$ rates at the bottom of the ITER divertor target plate ${ }^{1-4}$. Particulates can be produced from deposited layers by plasma erosion, ELMs and disruptions. Such particulates have been collected from current tokamaks during maintenance periods and analyzed ${ }^{5-9}$. Tokamak dust may be radioactive from tritium or activated metals, toxic and /or chemically reactive with steam or air. The large surface area associated with dust can greatly amplify its chemical reactivity. The hazard of dust depends on its quantity, composition, particle size, and temperature. Dust generation in next step devices will increase with the large scale-up in duty cycle and this has important safety consequences ${ }^{1}$. In a loss of coolant accident beryllium dust can react with steam to form hydrogen. For ITER to avoid the hazard of hydrogen explosions, the inventory of beryllium dust residing in the grooves of the tungsten divertor armor is limited to $10-20 \mathrm{~kg}$. A second limit is set at a few hundred $\mathrm{kg}$ for dust that could be mobilized during an accident and escape causing a radiological hazard. However demonstrating compliance with these limits is problematic due to lack of suitable diagnostics. Measuring the dust inventory is a challenge in existing machines let alone one with the radiological environment and scale of $\operatorname{ITER}^{10,11}$.

Good wall conditions are well known to be key to plasma performance in tokamaks, however the effect of in-vessel dust on performance is not known due to lack of real time dust diagnostics. Incandescent particles can sometimes be observed in tokamak discharges. Carbon plasma facing components that have been retrieved from tokamaks readily generate dust when handled and tritium can be detected with great sensitivity by liquid scintillation counting techniques (though not in real-time). Stringent precautions are taken to avoid personnel exposure as airborne tritiated dust could be trapped inside the lung alveoli with a biological residence time much longer than that of tritiated water or tritium gas ${ }^{12,13}$. 
When handling particulates or dusty components, technicians have observed tritiated dust appearing to 'boil' or 'climb up hill' however controlled experiments have been lacking. Personnel handling plutonium oxide powder have also observed its unusual mobility ${ }^{14}$; in this case the plutonium alpha emission leaves the particles charged. These phenomena have not been documented however.

\section{Experimental results}

The Tokamak Fusion Test Reactor (TFTR) operated with deuterium-tritium plasmas in the period 1993 - 1997 and deuterium and tritium were codeposited with carbon inside the vacuum vessel ${ }^{15}$. After the end of plasma operations selected tiles were removed from the inner bumper limiter for analysis ${ }^{16}$. Samples of the codeposited material were mechanically scraped from carbon-fiber-composite (CFC) tile KB3 (Fig.1). The designation KB3 identifies the inner limiter segment at bay $\mathrm{K}, 2^{\text {nd }}$ column from left, third tile up from bottom. Material was scraped both from the plasma facing surface and a heavy codeposit on the side of a diagnostic penetration. Some of the material was loaded into a standard $10 \mathrm{ml}$ glass liquid scintillation vial $17 \mathrm{~mm}$ diameter, $57 \mathrm{~mm}$ high with a plastic cap. Material was also scraped from TFTR tiles MA12 and QD13. These tiles had been retrieved from the tokamak before tritium fuel was introduced and had a codeposited deuterium/carbon layer. A third sample of particles was scraped from an unused piece of CFC material.

When sliding the vial containing the tritiated particles across a coated fabric (Herculite ${ }^{\mathrm{TM}}$ ) it was observed that the particles spontaneously levitated in a remarkable fountain inside the vial. Rubbing the plastic cap of the vial with either latex or neoprene gloves also stimulated a fountain of particles that lasted 10-15 seconds. Control experiments were performed in an identical fashion but using deuterated particles from tiles MA12 and QD13 and also carbon particles from the unused CFC material. For these latter cases some evidence of static charge was apparent as the particles clung to the inside surface of the glass vial, but there was no fountain of particles when the cap or vial was rubbed.

This phenomenon was recorded by a low power digital microscope ${ }^{17}$ configured to record videos at 8 frames/sec. The vial plastic cap was rubbed for about 5 seconds and the vial then set down in the view of the microscope. The top three images in Fig. 2 show consecutive frames 
from the control experiment using the deuterated particles. No motion is apparent. This lack of motion was also the case for carbon particles scraped from a piece of CFC material that had not been used in a tokamak (the same type of material as tile KB3). The non-tritiated carbon dust simply remains stationary. In contrast the lower 6 images show consecutive frames of tritiated dust from tile KB3. Some flakes are stuck to the inside of the vial; others are seen to move from frame to frame. The phenomenon is clearer of course when seen by eye or as a video. The dust 'fountain' terminated after 10-15 seconds, but could be repeated by rubbing the plastic cap again.

\section{Discussion}

Tritium undergoes radioactive decay with the ejection of a beta electron leaving behind a positive charge. Evidently rubbing the glass on the Herculite ${ }^{\mathrm{TM}}$ resulted in the creation of a static electric field in the vial, which then attracted the particles. After 10-20 seconds the electric field was presumably neutralized by ambient ions and the particles stopped moving.

The visible particles are of dimension $1-2 \mathrm{~mm}$ down to the limiting resolution of 0.18 $\mathrm{mm}$ ( 1 pixel). The tritium content of flakes from TFTR tiles was previously measured to be 3 $\mathrm{Ci} / \mathrm{g}^{18}$. A $1 \mathrm{~mm} \times 1 \mathrm{~mm} \times 0.1 \mathrm{~mm}$ flake of density $2 \mathrm{~g} / \mathrm{cm}^{3}$ then contains $0.6 \mathrm{mCi}$, which will generate $2 \times 10^{7}$ beta electrons/sec. The codeposit material is highly porous and betas generated within a few microns of the surface can escape. Charge will build up continuously on the particle until balanced by a return current. For levitating particles, the product of the charge and the static electric field are high enough overcome the gravitational force. For the above flake a force of about $2 \times 10^{-6}$ newtons is needed for levitation and from the equation of electrostatic force, $\mathrm{F}=\mathrm{qE}$, this could be provided by a charge of $1.3 \times 10^{7}$ electrons $\left(2.1 \times 10^{-12}\right.$ coulombs $)$ in an electric field of $1 \times 10^{6}$ volts $/ \mathrm{m}$.

In summary, the charge induced by the tritium beta decay greatly increases the mobility of tritiated particles enabling them to levitate in the presence of a static electric field. Ambient static charges are ubiquitously present on plastic materials and these materials will become quickly contaminated in the presence of tritiated dust. Normal occupational precautions, such as protective clothing and positive airflow are adequate to control the spread of such dust in a controlled environment such as a fume hood. In accident scenarios, ambient static electric fields 
will facilitate the spread of tritiated dust and this should be considered in safety analyses and potential clean-up methods.

\section{Acknowledgments}

We thank A. Planetta and the PPPL health physics group for supporting these measurements. Financial support was provided by U.S. DOE Contract Nos. DE-AC02$76 \mathrm{CH} 0307$. 


\section{References:}

1 G. Federici C. H. Skinner et al., "Plasma-material interactions in current tokamaks and their implications for next step fusion reactors" Nucl. Fus. 41, 1967 (2001).

2 C. H. Skinner and G. Federici, "Tritium Issues in Next Step Devices” in Advanced Diagnostics for Magnetic and Inertial Fusion, P. Stott et al., eds., Kluwer Academic/Plenum, New York (2002) p. 277.

3 J. N. Brooks et al., "Erosion/redeposition analysis:status of modeling and code validation for semi-detached tokamak edge plasmas” J. Nucl. Mater. 266-269, 58, (1999).

4 G. Federici et al., "Assessment of erosion and tritium codeposition in ITER-FEAT" J. Nucl. Mater., 290-293, 260, (2001).

5 W. J. Carmack, et al., "Characterization and analysis of dusts produced in three experimental tokamaks: TFTR, DIII-D, and Alcator C-Mod” Fusion Eng Des 51-2: 477484 (2000).

6 J. Winter, "Dust in fusion devices-experimental evidence, possible sources and consequences" Plasma Phys. Control Fusion 40, 1201 (1998).

7 A. T. Peacock et al., "Dust and flakes in the JET MkIIa divertor, analysis and results" J. Nucl. Mater. 266-269, 423 (1999).

8 Ph. Chappuis et al., "Dust characterization and analysis in Tore-Supra” J. Nucl. Mater $290-293,245$ (2001).

$9 \quad$ M Rubel et al., "Dust particles in controlled fusion devices: morphology, observations in the plasma and influence on the plasma performance" Nucl. Fus., 41, 1087, (2001).

10 G. F. Counsell and C. H. Wu, "In-situ detection and removal of carbon debris - a challenge for the next step fusion device” Physics Scripta. TIC116, 1 (2001).

11 G.T. Razdobarin, G. Federici, V.M. Kozhevin, E.E. Mukhin, V.V. Semenov, S.Y. Tolstyakov, "Detecting dust on plasma-facing components in a next-step tokamak using a laser-induced breakdown spectroscopy technique", Fusion Sci. \& Technol., 41, 32-43 (2002). 
12 Y.S. Cheng, Y. Zhou, C.A. Gentile, and C. H. Skinner, "Characterization of carbon tritide particles in a tokamak fusion reactor" Fusion Sci \& Technol. 41, 867 (2002).

13 B. Patel, S. Knipe, P. Macheta, A. Peacock, "Radiological properties of tritiated dusts and flakes from the JET tokamak" Proceedings of the $18^{\text {th }}$ IEEE/NPSS Symposium on Fusion Engineering, IEEE, Piscataway, NJ 08855, p. 338 (1999)

14 T. Venetz, Pacific Northwest National Laboratory, personal communication

15 C. H. Skinner, et al., "Modeling of tritium retention in TFTR" J. Nucl. Mater. 266- 269, 940 (1999).

16 C. H. Skinner, et al., "Studies of tritiated co-deposited layers in TFTR" J. Nucl. Mater. 290-293, 486 (2003).

17 National Optical \& Scientific Instruments Model DC3-420T .

18 C. H. Skinner, C. A. Gentile, M. M. Menon, R. E. Barry., "Flaking of co-deposited hydrogenated carbon layers on the TFTR limiter" Nucl. Fus. 39, 1081 (1999). 


\section{Figure Captions:}

Fig. 1 TFTR tile KB3. The curved surface of the diagnostic penetration is shown (i) with the codeposit and (ii) after the codeposit was mechanically removed.

Fig. 2 Consecutive stills from a microscope video at 8 frames/s of particles in a glass vial. The top three images are particles scraped from a codeposit formed from exposure to deuterium plasmas. The bottom six images are consecutive stills of particles from codeposits from deuterium-tritium plasmas. While some particles are stuck to the side of the vial in both cases, for the tritiated particulates in the lower six frames, the image changes dynamically from frame to frame showing the levitation of particles under the static electric field. 

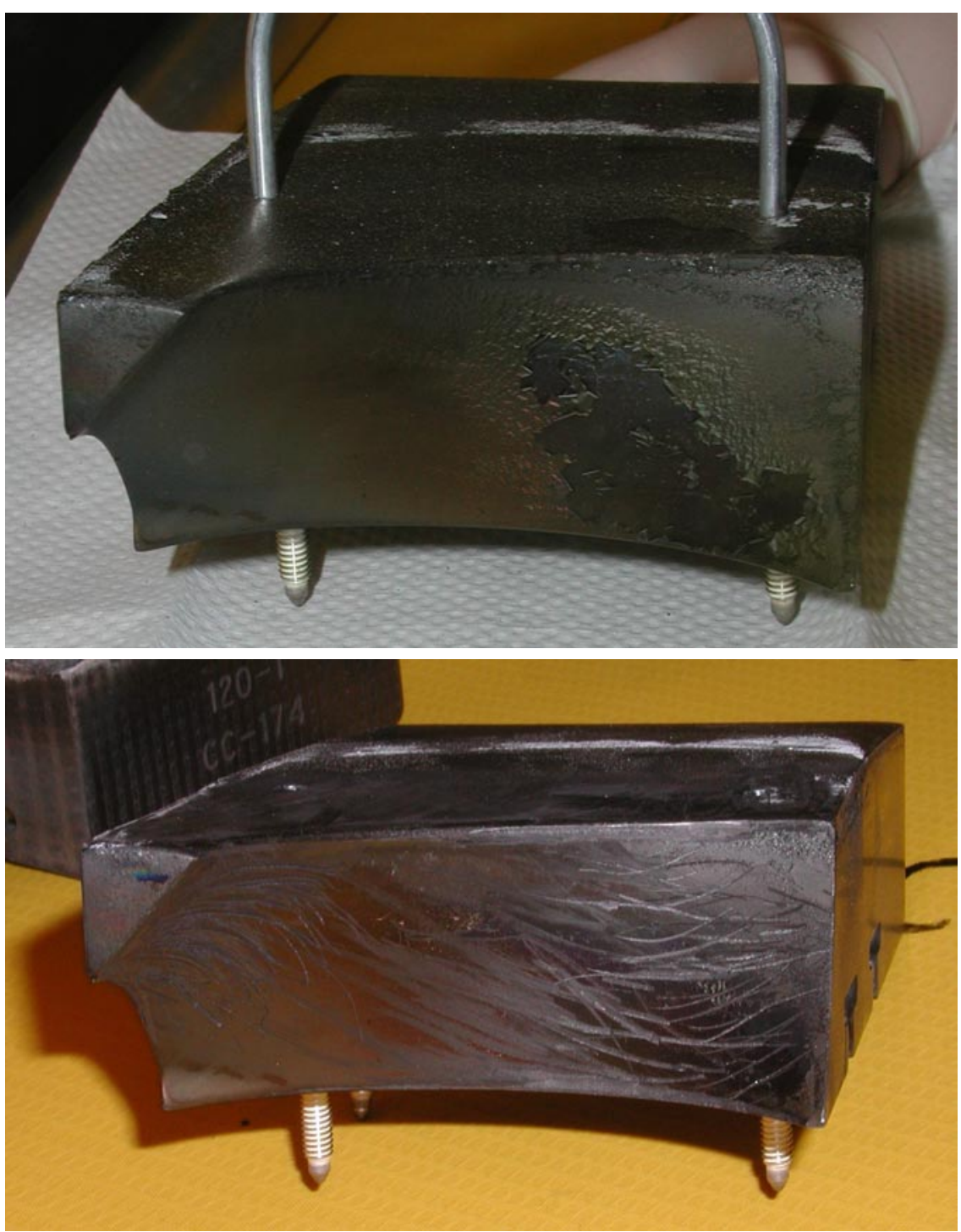

Fig. 1 TFTR tile KB3 The curved surface of the diagnostic penetration is shown (i) with the codeposit and (ii) after the codeposit was mechanically removed. 

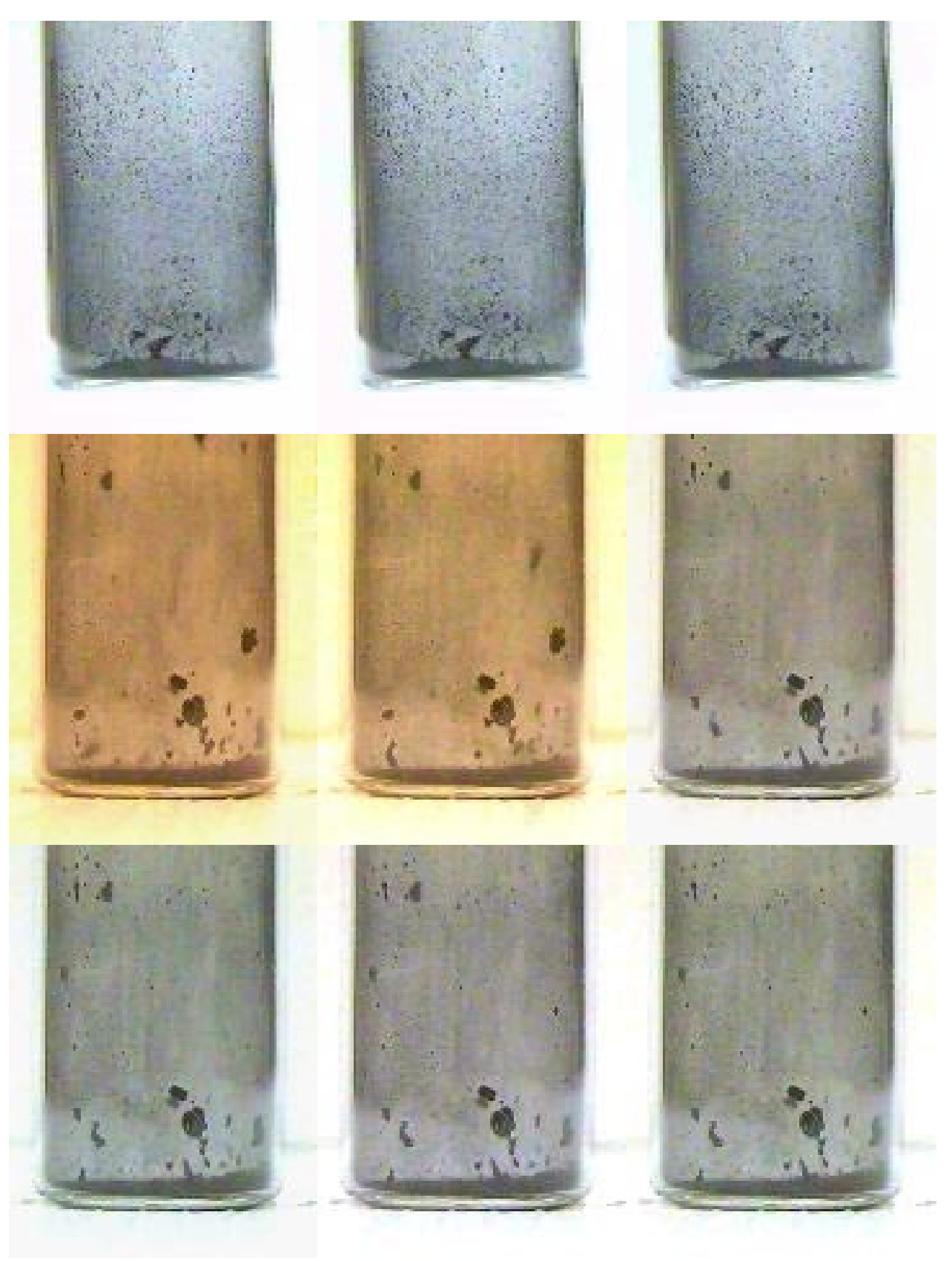

Fig. 2 Consecutive stills from a microscope video at 8 frames/s of particles in a glass vial. The top three images are particles scraped from a codeposit formed from exposure to deuterium plasmas. The bottom six images are consecutive stills of particles from codeposits from deuterium-tritium plasmas. While some particles are stuck to the side of the vial in both cases, for the tritiated particulates in the lower six frames, the image changes dynamically from frame to frame showing the levitation of particles under the static electric field. 


\section{External Distribution}

Plasma Research Laboratory, Australian National University, Australia

Professor I.R. Jones, Flinders University, Australia

Professor João Canalle, Instituto de Fisica DEQ/IF - UERJ, Brazil

Mr. Gerson O. Ludwig, Instituto Nacional de Pesquisas, Brazil

Dr. P.H. Sakanaka, Instituto Fisica, Brazil

The Librarian, Culham Laboratory, England

Mrs. S.A. Hutchinson, JET Library, England

Professor M.N. Bussac, Ecole Polytechnique, France

Librarian, Max-Planck-Institut für Plasmaphysik, Germany

Jolan Moldvai, Reports Library, MTA KFKI-ATKI, Hungary

Dr. P. Kaw, Institute for Plasma Research, India

Ms. P.J. Pathak, Librarian, Insitute for Plasma Research, India

Ms. Clelia De Palo, Associazione EURATOM-ENEA, Italy

Dr. G. Grosso, Instituto di Fisica del Plasma, Italy

Librarian, Naka Fusion Research Establishment, JAERI, Japan

Library, Plasma Physics Laboratory, Kyoto University, Japan

Research Information Center, National Institute for Fusion Science, Japan

Dr. O. Mitarai, Kyushu Tokai University, Japan

Dr. Jiangang Li, Institute of Plasma Physics, Chinese Academy of Sciences, People's Republic of China

Professor Yuping Huo, School of Physical Science and Technology, People's Republic of China

Library, Academia Sinica, Institute of Plasma Physics, People's Republic of China

Librarian, Institute of Physics, Chinese Academy of Sciences, People's Republic of China

Dr. S. Mirnov, TRINITI, Troitsk, Russian Federation, Russia

Dr. V.S. Strelkov, Kurchatov Institute, Russian Federation, Russia

Professor Peter Lukac, Katedra Fyziky Plazmy MFF UK, Mlynska dolina F-2, Komenskeho Univerzita, SK-842 15 Bratislava, Slovakia

Dr. G.S. Lee, Korea Basic Science Institute, South Korea

Institute for Plasma Research, University of Maryland, USA

Librarian, Fusion Energy Division, Oak Ridge National Laboratory, USA

Librarian, Institute of Fusion Studies, University of Texas, USA

Librarian, Magnetic Fusion Program, Lawrence Livermore National Laboratory, USA

Library, General Atomics, USA

Plasma Physics Group, Fusion Energy Research Program, University of California at San Diego, USA

Plasma Physics Library, Columbia University, USA

Alkesh Punjabi, Center for Fusion Research and Training, Hampton University, USA

Dr. W.M. Stacey, Fusion Research Center, Georgia Institute of Technology, USA

Dr. John Willis, U.S. Department of Energy, Office of Fusion Energy Sciences, USA

Mr. Paul H. Wright, Indianapolis, Indiana, USA 
The Princeton Plasma Physics Laboratory is operated by Princeton University under contract with the U.S. Department of Energy.

\author{
Information Services \\ Princeton Plasma Physics Laboratory \\ P.O. Box 451 \\ Princeton, NJ 08543
}

Phone: 609-243-2750

Fax: 609-243-2751

e-mail: pppl_info@pppl.gov

Internet Address: http://www.pppl.gov 